JNPA. XXVI(1) 2012

\title{
Research \\ Pattern of adverse drug reactions reported to the regional Pharmacovigilance center at Nepal Medical College and Teaching Hospital, Kathmandu
}

\author{
Durga Bista $^{1^{*}}$, Bal Ram Shrestha ${ }^{2}$, Prakash Rai ${ }^{1}$, Akhilesh Chandra Jauhari ${ }^{1}$, Vishnu Kant \\ Kulshrestha ${ }^{1}$
}

\author{
1 Department of Clinical Pharmacology, Nepal Medical College Teaching Hospital, Jorpati \\ Kathmandu, Nepal \\ 2 Department of Internal Medicine, Nepal Medical College Teaching Hospital, Jorpati \\ Kathmandu Nepal
}

\begin{abstract}
The Pharmacovigilance program in Nepal is at very preliminary stage. Present study analyzed the pattern, causality, severity and preventability of the reported adverse drug reactions (ADRs) to the Pharmacovigilance center at Nepal Medical College and Teaching Hospital (NMCTH), from June 2007 to July 2011. A total of 40 ADR cases were reported, among which $23(57.5 \%)$ were in males and $17(42.5 \%)$ in females. Nineteen (47.5\%) ADRs were reported in the age group between 21-40 years. Department of Medicine reported 12(30\%) ADRs. Among the total ADRs, antibiotics $[n=17,(42.5 \%)]$ were responsible for most of the reactions followed by non steroidal anti-inflammatory drugs $[\mathrm{n}=5,(12.5 \%)]$. Most of the drugs were found to affect dermatological system $[\mathrm{n}=14,(35 \%)]$. Carbamazepine accounted for 5 (12.5\%) ADRs. The causality assessment showed $34(85 \%)$ of the ADRs to have a 'probable' relationship with the suspected reaction.
\end{abstract}

Key Words: Adverse Drug Reactions, Pharmacovigiolance, ADR reporting

\section{Introduction}

Harmful, unintended reactions to medicines that occur at doses normally used for treatment are called adverse drug reactions (ADRs). ADRs are among the leading causes of death in many countries [1]. A survey from Canada observed that $19 \%(162, n=863)$ of the admissions exhibited at least one drug-related adverse patient event at the time of hospitalization. During the study ADRs were responsible for many drug-related adverse events (48\%) [2].

A multicentric study conducted on Nepal revealed that $0.64 \%$ of the hospital admissions were related to drugs [3]. Similarly, another study conducted in different hospitals of Nepal revealed the prevalence of $0.86 \%$ of ADR from 4287 patients studied for 5 months [4]. Drug related complications are often ignored in developing countries like ours. People often put their lives at risk as they do not know the consequences of irrational drug use without proper patient counseling and expert advices. Pharmacovigilance is the science and activities relating to the detection, assessment, understanding and prevention of adverse effects or any other possible drug-related problems. Recently, it also includes herbals, traditional and complementary medicines, blood products, biologicals, medicinal devices and vaccines as well [5].

Till now there is lack of reports on the incidence of ADRs in Nepal and we have to rely totally on data from other countries. The concept of Pharmacovigilance (PV) was started in the year 2004 in Nepal. Department of Drug Administration (DDA) is a National center for ADR monitoring

*Corresponding author: durgabista40@ hotmail.com

Department of Clinical Pharmacology

Nepal Medical College Teaching Hospital, Jorpati Kathmandu, Nepal 
JNPA. XXVI(1) 2012

and there are regional centers under the DDA. Nepal Medical College and Teaching Hospital (NMCTH) is a tertiary care teaching hospital in central Nepal and was recognized as one of the regional centers, to report ADRs to DDA, since 2007. Since the, Department of Clinical Pharmacology at NMCTH has been coordinating as a Pharmacovigilance center, to collected the suspected ADRs from all the departments. Therefore the present study was carried out to find out the pattern of the adverse drug reactions reported to the center as well as to carry out the causality, severity, and preventability of the reported adverse drug reactions.

\section{Materials and Methods}

Study Design: A cross sectional study evaluating the pattern of ADRs.

Study site: Nepal Medical College and Teaching Hospital, Jorpati Kathmandu, Nepal.

Tools: Adverse drug reaction reporting form designed by the Pharmacovigilance center, NMCTH All ADRs reported to the PV center of NMCTH since June 2007 to July 2011 were documented. Health care professionals (Medical Doctors, Nurses, Medical Students and Pharmacists) were briefed about the process of reporting ADRs. Follow-up visits were made to different wards to encourage reporting ADRs. Each and every reported case was thoroughly revised and necessary information was gathered from the patient's chart from Medical record section of the hospital. All cases were analyzed for the Causality, Severity and Preventability as per the Naranjo, Hartwig and Modified Schumock and Thronton scales respectively. Few of these cases have also been reported to DDA via Vigiflow software. DDA then sends those reports to Uppsala Monitoring center (UMC), Sweden: a WHO recognized international center for ADR reporting.

\section{Results}

During four years of time, pharmacovigilance center at NMCTH received a total of 40 ADRs. The results were as follows

Fig I: ADRs reported by the different departments of NMCTH

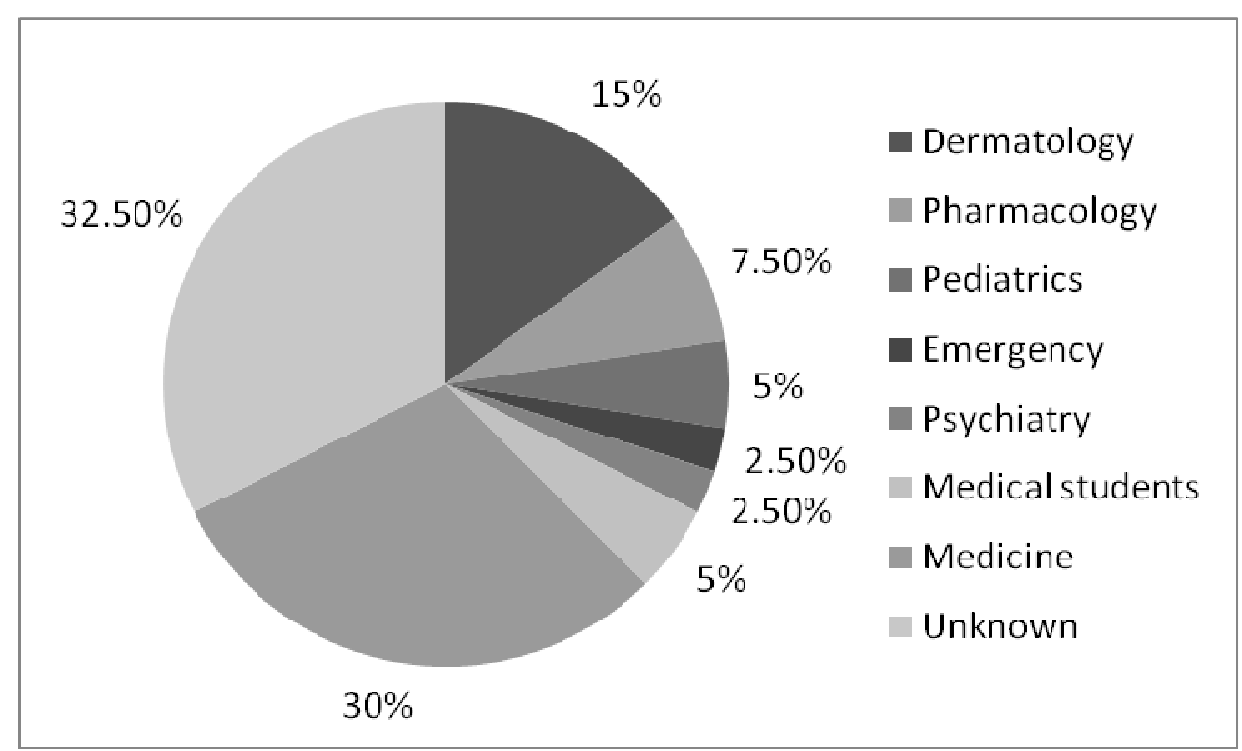


JNPA. XXVI(1) 2012

Fig II: Sex wise distribution of patients suffering from ADRS at NMCTH

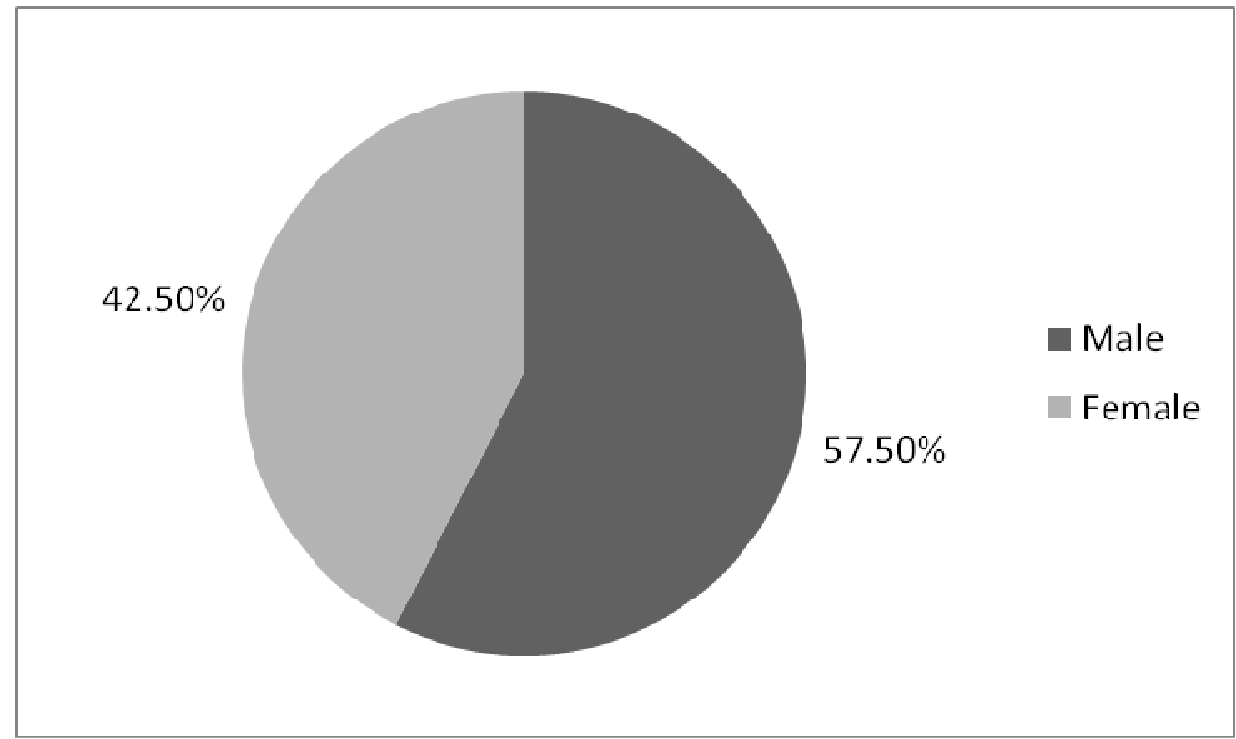

Fig III: Age wise distribution of ADRs reported at NMCTH

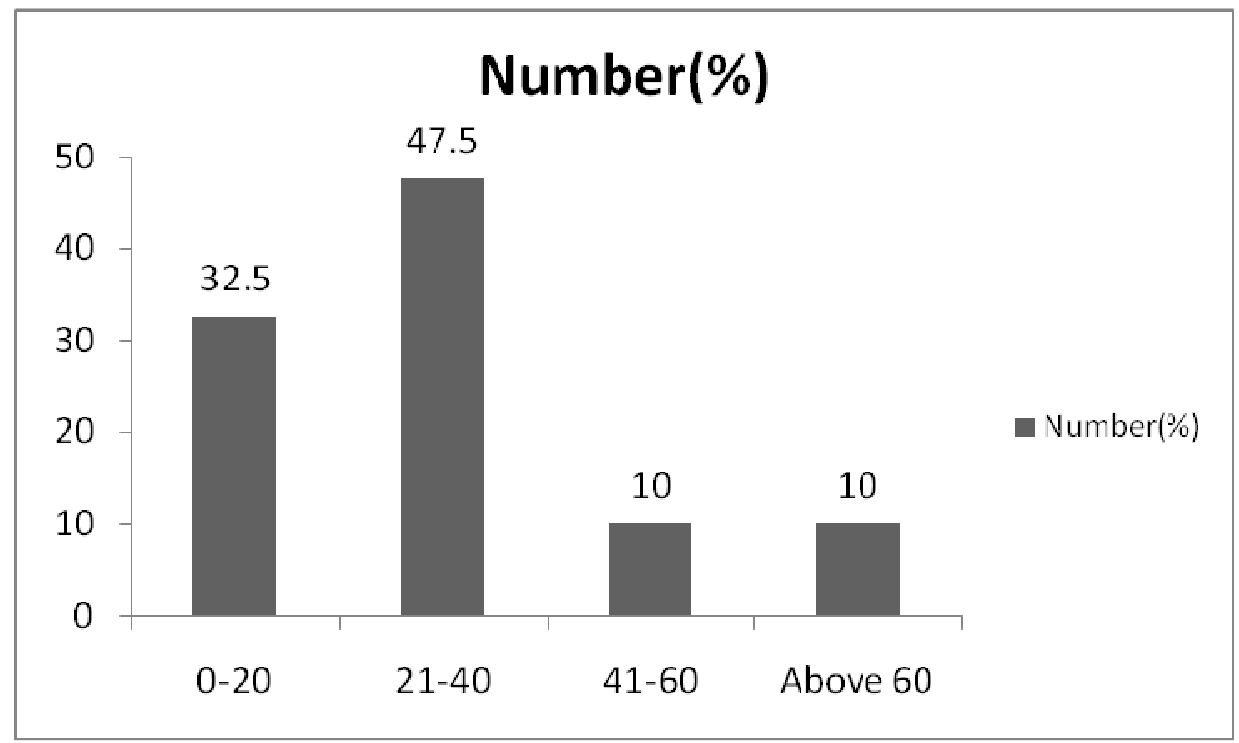


JNPA. XXVI(1) 2012

Fig IV: Drug category responsible for ADRs reported at NMCTH

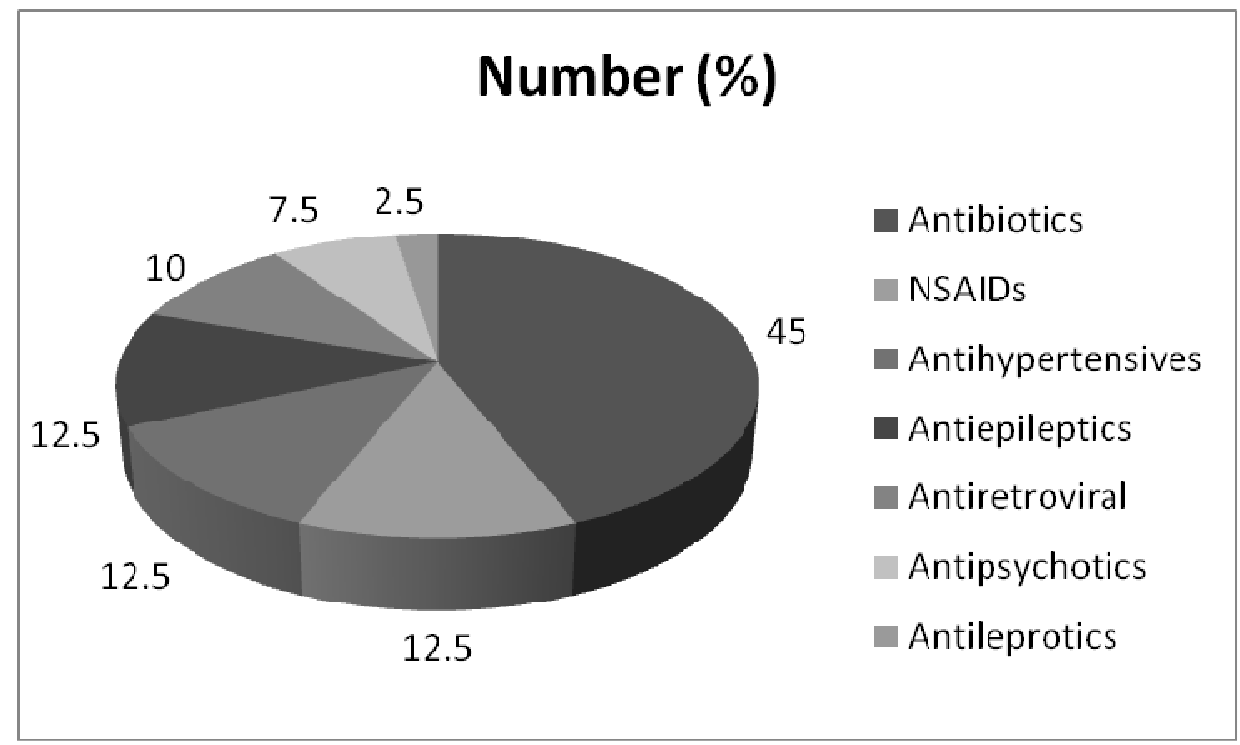

Fig V: Systems affected by ADRs reported at NMCTH

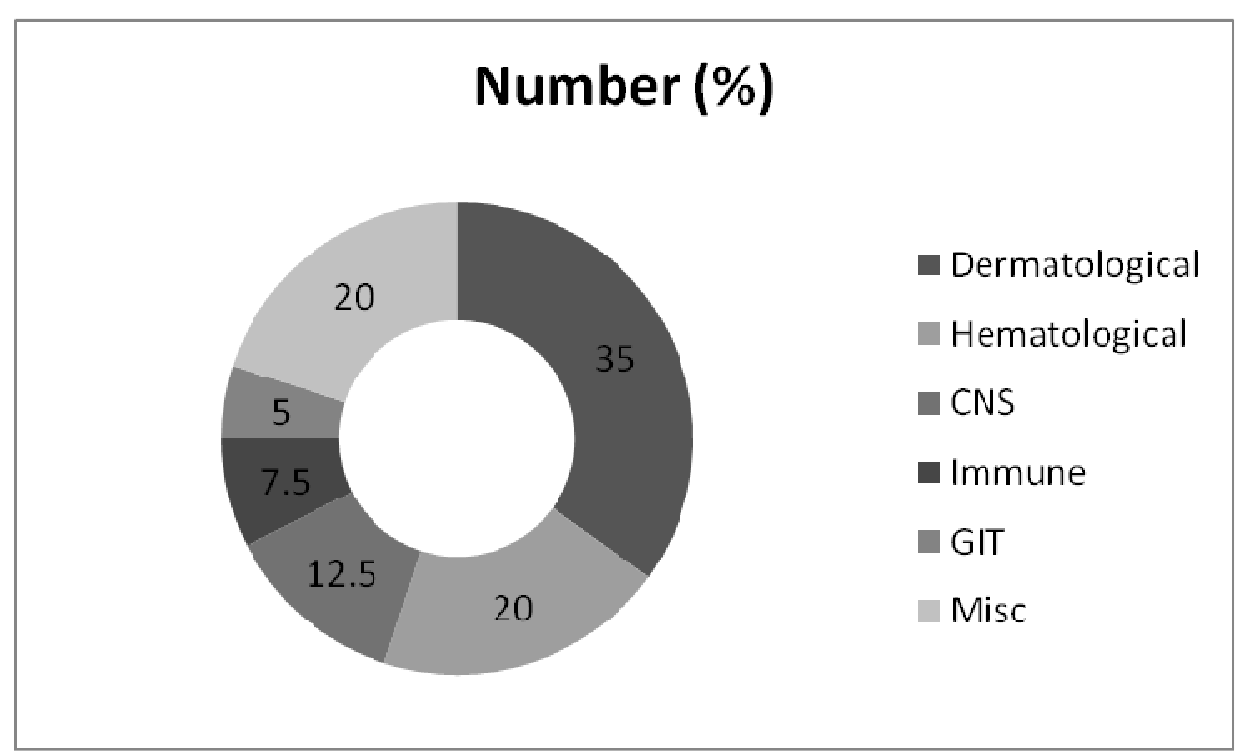


Fig VI: Causality assessment of ADRs reported at NMCTH

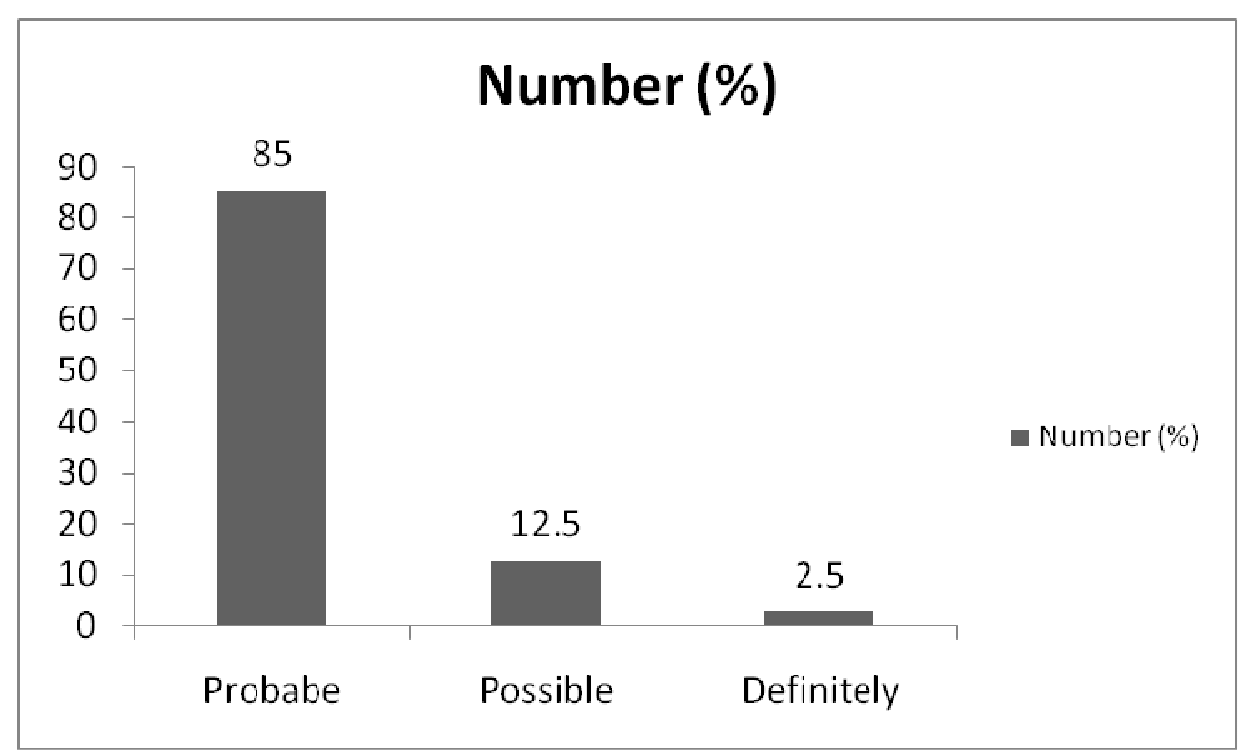

Similarly, the severity assessment found 12 (30\%) ADRs to be of 'moderate (level 3)', 11 $(27.5 \%)$ to be 'mild (level 1)', 7 (17.5\%) to be of 'mild (level 2) and 'moderate (level 4(a))' respectively, $2(5 \%)$ to be 'moderate level $4(\mathrm{~b})$ ' and finally $1(2.5 \%)$ ADR was of 'severe level (5)' type. The preventability assessment showed, 35 (87.5\%) ADRs to be 'Non Preventable', while $5(12.5 \%)$ ADRs were of 'probably preventable' type.

Table I: Top ten drugs responsible for the ADRs

\begin{tabular}{|l|c|}
\hline \multicolumn{1}{|c|}{ Drugs } & No. of reports \\
\hline Carbamazepine & 5 \\
\hline Zidovudine & 4 \\
\hline Ibuprofen & 3 \\
\hline Azithromicin & 3 \\
\hline Amlodipine & 3 \\
\hline Ofloxacin & 3 \\
\hline Amoxycillin & 2 \\
\hline Enalapril & 2 \\
\hline Nimesulide & 2 \\
\hline Ceftriaxone & 2 \\
\hline *Others (one each) & 11 \\
\hline
\end{tabular}

* Amoxicillin+ Clavulanic acid, Gabapentin, Dapsone, Ethambutol, Cloxacillin, Lithium, Sulphamethoxaxole+Trimethoprim, Chloramphenicol, Rifampicin, Anti-tubercular drugs 
JNPA. XXVI(1) 2012

\section{Discussion}

Our study analyses the pattern, causality, severity and preventability of the ADRs reported since July 2007 to July 2011, to the regional Pharmacovigilance center at NMC.

Out of 40 ADR cases, $57.5 \%(n=23)$ were found among males and $42.5 \%(n=17)$ in females. Other studies however have shown females to be more prone to ADRs than males [6, 7]. Small study population of our study might have influenced this result of the study.

Our study found maximum number $47.5 \%(\mathrm{n}=19)$ of patients suffering from ADRs between the age groups of 21-40 years. The result is similar to the findings in the study by Subish et al conducted in Nepal [8] and by Martin et al as well [7]. We found antibiotics were responsible for majority $42.5 \%(\mathrm{n}=17)$ of ADRs followed by nonsteroidal anti-inflammatory drugs (NSAIDS) $12.5 \%(\mathrm{n}=5)$, antihypertensive $12.5 \%(\mathrm{n}=5)$, antiepileptic $12.5 \%(\mathrm{n}=5)$, antiviral $10 \%(\mathrm{n}=4)$, antipsychotic $7.5 \%$ $(n=3)$, and antileprotic $2.5 \%(n=1)$ respectively. Our result is similar to the findings of study by Subish et al and Jha et al in Nepal. [4, 9]

Dermatological system $n=14(35 \%)$ was the most common organ system followed by hematological system $n=8(20 \%)$ and this finding is consistent with the reports of an Indian study [10].

The causality assessment revealed that most of the ADRs belonged to "probable" $\mathrm{n}=34(85 \%)$ followed by possible $n=5(12.5 \%)$ and definite $n=1(2.5 \%)$. Upon severity assessment Moderate (level 3) type accounted for $n=12(30 \%)$ of the reports. The ADR requires that the suspected drug be withheld, discontinued otherwise changed, and/or on antidote or other treatment is required. There is no increase in length of stay due to ADR.

Table II: Types of ADRs reported

\begin{tabular}{|l|c|}
\hline Types of ADR reported & No. of reports (\%) \\
\hline Maculopapular rashes & 8 \\
\hline Severe anemia & 4 \\
\hline Thrombocytopenia & 3 \\
\hline Stevens-Johnson Syndrome & 3 \\
\hline Pedal edema & 3 \\
\hline Conversion Disorder & 2 \\
\hline Weight gain & 1 \\
\hline Tooth discoloration & 1 \\
\hline Gingival hypertrophy & 1 \\
\hline Generalized edema & 1 \\
\hline Acne & 1 \\
\hline Fixed drug eruption & 1 \\
\hline Morbilliform eruption & 1 \\
\hline Itching, lip swelling & 1 \\
\hline Dry cough & 1 \\
\hline Mood changes & 1 \\
\hline Insomnia & 1 \\
\hline Dizziness & 1 \\
\hline Abdominal cramps and pain & 1 \\
\hline Convulsion disorder & 1 \\
\hline Thrombocytopenic purpura & 1 \\
\hline
\end{tabular}


JNPA. XXVI(1) 2012

Also, mild consisted of about a quarter [n=11, (27.5\%)] of the total reports of ADRs. Preventability assessment revealed $n=35(87.5 \%)$ to be of non preventable type of ADRs while $n=5(12.5 \%)$ were of preventable type. Even though the ADRs are of unpredictable type their occurrence can be minimized by good history taking and patient counseling. In a country like Nepal where even antibiotics are available very freely as an over the counter (OTC) drug, intensive monitoring of ADRs requires a tremendous demand. There has to be regular training programs conducted for the health care professionals for making them aware about ADRs and reduce the occurrence of ADRs.

\section{Conclusion}

Pharmacovigilance related activities needs to be strengthened in Nepal with the active participation of health care professionals. There has to be regular training programs on Pharmacoviliance. National Pharmacovigilance center should take an initiative for this noble effort.

\section{Acknowledgement}

We highly acknowledge the help from all the reporters who actively took part to report the ADRs. We are especially thankful to Dr Subish Palain, Associate Professor, College of Medical Sciences, Bharatpur, Nepal for his cooperation on preparation of the manuscript. 
JNPA. XXVI(1) 2012

\section{References}

1. Medicines: Safety of Medicines- adverse drug reactions. Geneva: World Health Organization: 2008. Available at http://www.who.int/mediacentre/factsheets/fs293/en/index.html (Accessed $14 / 09 / 2011)$

2. Grymonpre RE, Mitenko PA, Sitar DS, Aoki FY, Montgomery PR. Drug associated hospital admissions in older medical patients, J Am Geriatr Soc, 36: 1092-8, 1988.

3. Shrestha R, Shakya S, Bista D, Shrestha RK, Khan GM, Joshi S, Rao BS. Case studies of hospitalized patients due to drug related complications, Kathmandu Univ J of Sci Eng Technol, 2(1): 2006.

4. Jha N, Bajracharya O, Namgyal T. Prevalence of adverse drug reactions with commonly prescribed drugs in different hospitals of Kathmandu valley. Kathmandu Univ Med $J$ (KUMJ). 5(4):504-10, 2007.

5. The Importance of Pharmacovigilance - Safety Monitoring of Medicinal Products. Geneva: World Health Organization: 2002. Available at http://apps.who.int/medicinedocs/en/d/Js4893e/3.html. (Accessed 14/09/2011).

6. Martin RM, Biswas PN, Freemantle SN, Pearce GL, Mann RD. Age and sex distribution of suspected adverse drug reactions to newly marketed drugs in general practice in England: analysis of 48 cohort studies, 46(5): 505-11, 1998.

7. Kheirollah gholami, Shadi Ziaie, Gloria Shalviri. Adverse drug reactions induced by cardiovascular drugs in outpatients, Pharmacy Practice (Internet), 6 (1): 2008

8. Subish P, P M and Pr S.. Systemic adverse drug reactions: A preliminary report from the regional pharmacovigilance center, western Nepal, Pak J. Pharm. Sci., 21 (4): 465-467, 2008.

9. Palaian S, Ibrahim MIM P. Pattern of adverse drug reaction reported by the community pharmacist in Nepal. Pharmacy Practice (Internet), 8(3): 201-207, 2010.

10. Jimmy Jose, Padma G.M. Rao. Pattern of adverse drug reactions notified by spontaneous reporting in an Indian tertiary care teaching hospital. Pharmacological Research, 54: 226-233, 2006. 